\title{
Effect of ultrasound-enhanced fat separation on whey powder phospholipid composition and stability
}

\author{
Amir E. Torkamani, ${ }^{*} \dagger^{1}$ Pablo Juliano, ${ }^{* 2}$ Peter Fagan, ${ }^{*}$ Rafael Jiménez-Flores, $\ddagger$ Said Ajlouni, $\dagger$ \\ and Tanoj K. Singh* \\ ${ }^{*}$ CSIRO Food and Nutrition Flagship, Werribee, VIC 3030, Australia \\ †Biosciences Section, Faculty of Veterinary and Agriculture Sciences, The University of Melbourne, Parkville, VIC 3010, Australia \\ †Dairy Products Technology Centre, College of Agriculture, Food \& Environmental Sciences, California Polytechnic State University, \\ San Luis Obispo 93407
}

\section{ABSTRACT}

Fat from freshly pasteurized liquid whey was partially separated by gravity for 5,10 , and $30 \mathrm{~min}$, with and without simultaneous application of ultrasound. Ultrasound treatments were carried out at 400 and $1,000 \mathrm{kHz}$ at different specific energy inputs (23-390 $\mathrm{kJ} / \mathrm{kg}$ ). The fat-enriched top layers (L1) and the fatdepleted bottom layers (L2) were separately removed and freeze-dried. Nonsonicated and sonicated L2 powders were stored for $14 \mathrm{~d}$ at ambient temperature to assess their oxidative stability. Creaming was enhanced at both frequencies and fat separation increased with higher ultrasonic energy, extended sonication, or both. The oxidative volatile compound content decreased in defatted whey powders below published odor detection threshold values for all cases. Sonication had a minor influence on the partitioning of phospholipids with fat separation. The current study suggested that ultrasonication at high frequency enhanced fat separation from freshly pasteurized whey while improving whey powder oxidative stability.

Key words: ultrasound, whey, fat separation, stability, phospholipids

\section{INTRODUCTION}

Whey is a liquid by-product of cheese production, and its solids contain up to $13 \%$ protein. High protein content in whey makes it suitable for the development of functional and nutritional ingredient formulations used in a variety of products such drinks, infant formulae,

Received September 19, 2015.

Accepted February 17, 2016.

${ }^{1}$ Current affiliation: Food Technology Department, School of Industrial Technology, Universiti Sains Malaysia, Minden, 11800, Penang, Malaysia.

${ }^{2}$ Corresponding author: Pablo.Juliano@csiro.au sport supplements, and pharmaceuticals, among other whey-based ingredients. Whey powders may contain fat ranging from 2.5 to $8 \%$, which could adversely influence their functionality and flavor quality (Morr and Ha, 1993). Residual lipid affects whey powder functional properties such as gelation, solubility, emulsification, or foaming capacities. Autoxidative reactions of lipid can cause development of aged and stale off-flavors in whey powder during storage. In this instance, polar lipid species such as phospholipid fractions are more susceptible to lipid oxidation rather than neutral glyceride fraction (Morr and Ha, 1991).

Even though commercial centrifuges can remove a significant proportion of fat from liquid whey, they do not completely remove phospholipid fractions. Other commercial separation techniques such as membrane filtration require high pressures and cannot fully remove the entire whey lipids. Furthermore, membrane processes such as ultrafiltration often show limitations on fat separation process due to fouling of the membrane caused by the whey phospholipids (Morr and Ha, 1993). High-frequency ultrasound (400 to $2,000 \mathrm{kHz}$ ) has been recently studied as a technique for enhancing gravity separation of lipids from milk (Juliano et al., 2011, 2013a; Leong et al., 2014a,b) and oil-bearing materials (Juliano et al., 2013b, Leong et al., 2013). Unlike centrifugation, ultrasonic separation reactors do not require moving parts when adjusted to continuous processing lines.

Recent publications considered the application of high-frequency ultrasound to raw and recombined milk emulsions via single or multiple transducer configurations and showed the dependence of ultrasound-assisted gravity separation on frequency at similar energy densities (Juliano et al., 2011, 2013a). Further studies showed that gravity separation of cream from raw milk was better enhanced with 1,000 and $2,000 \mathrm{kHz}$ transducers at increasing sonication time and sound energy input at $25^{\circ} \mathrm{C}$ (Leong et al., 2014a,b). Milk fat globule aggregation at high frequencies is enhanced above threshold 
values for specific energy and acoustic pressure of 100 to $200 \mathrm{~kJ} / \mathrm{kg}$ and 50 to $200 \mathrm{kPa}$, respectively (Leong et al., 2014a,b).

The effect of ultrasonication on lipid oxidation in dairy products such as milk and whey has been investigated in a few studies (Riener et al., 2009; Chouliara et al., 2010; Marchesini et al., 2012; Juliano et al., 2014; Torkamani et al., 2014). Given that high rates of hydroxyl radical formation have been detected between 400 and $800 \mathrm{kHz}$, this is of concern for ultrasound separation applications in the high frequency range (Mason et al., 2011). Torkamani et al. (2014) reported that even though subsequent pasteurization promoted whey fat oxidation, ultrasound treatment of fresh whey $(20,400$, 1,000 , and $2,000 \mathrm{kHz}$ at $8.0-390 \mathrm{~kJ} / \mathrm{kg}$ ) at $37^{\circ} \mathrm{C}$ did not further affect the concentration of volatile compounds related to lipid oxidation (Torkamani et al., 2014). The authors did not detect changes in phospholipid or free fatty acid composition after ultrasound.

Little or no information is available in the published scientific literature on the ability of high-frequency ultrasound to assist gravity separation of fat from whey. It is also important to understand the effect on the composition and storage stability of the lipid fraction remaining in whey ingredients after ultrasound-assisted fat separation. Therefore, the aim of this study was to investigate the effect of ultrasound on gravity separation of fat from whey at selected high frequencies (400 and $1,000 \mathrm{kHz}$ ) and ultrasound processing times (5-30 min). The effect on lipid composition and stability on reduced-fat whey powders was studied by monitoring lipid oxidation volatile compounds during storage. The partitioning of phospholipid fractions by ultrasoundassisted gravity separation was also evaluated.
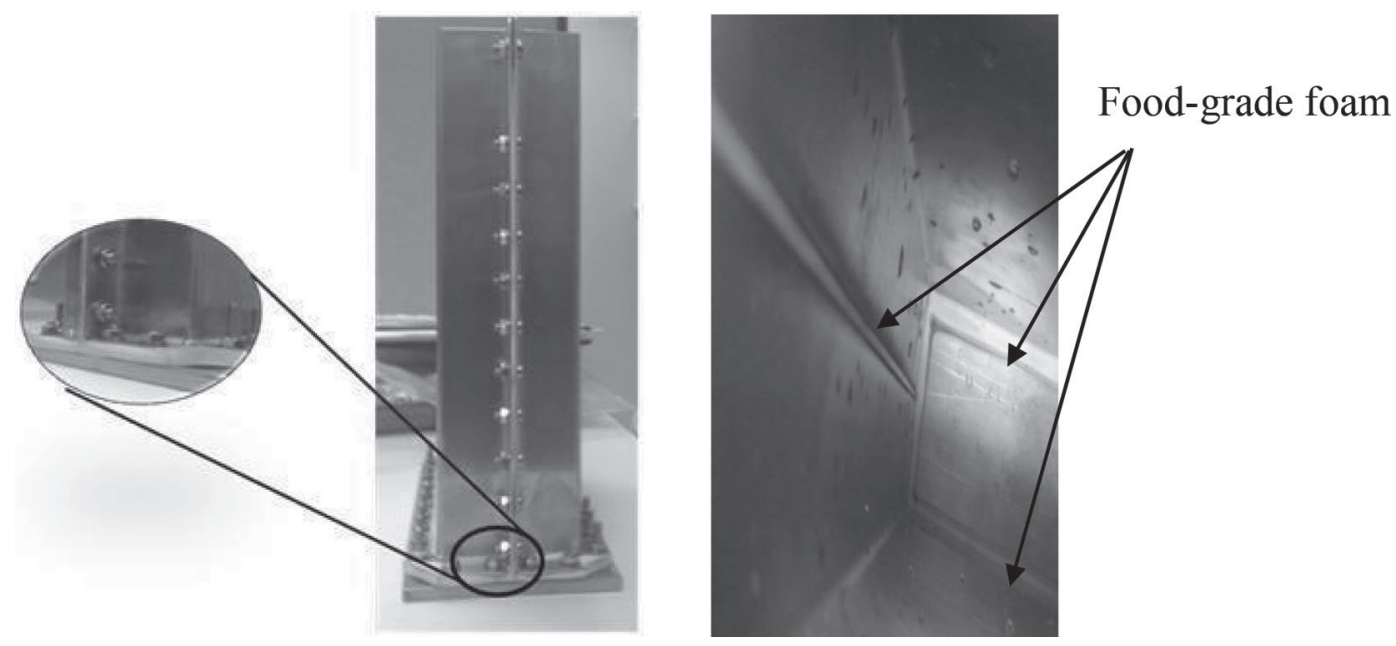

\section{MATERIALS AND METHODS}

\section{Sample Preparation and Handling}

Fresh Cheddar cheese whey (fat content $0.41 \%$ wt/ vol; TS $5.26 \% \mathrm{wt} / \mathrm{vol}$ ) was obtained from the Food Processing Centre at the Commonwealth Scientific and Industrial Research Organisation (CSIRO, Werribee, Victoria, Australia). Whey was immediately pasteurized at $73.9^{\circ} \mathrm{C}$ for $15 \mathrm{~s}$ in a plate heat exchanger. Pasteurized whey was cooled and stored at $5^{\circ} \mathrm{C}$ in 2 -L high-density polyethylene bottles with polystyrene caps in the dark and processed the same day.

\section{Ultrasound Reactor Setup}

A rectangular ultrasound reactor constructed from stainless steel was used (Figure 1). The plates were connected with screws instead of being welded to prevent erosion of welding material into whey during ultrasound treatment. The reactor was kept leak proof by inserting food-grade foam on plate intersections through the connecting points (Figure 1). The reactor was built in the smallest dimensions possible $(250 \times 180 \times 80 \mathrm{~mm})$ to maximize the effect of ultrasound waves and also fit the transducers.

The treatments were carried out by inserting submersible stainless-steel plate transducers (with an active area of $100 \times 100 \mathrm{~mm}$ ) operating at 400 and 1,000 $\mathrm{kHz}$ (Sonosys Ultraschallsysteme $\mathrm{GmbH}$, Neuenburg, Germany; Figure 2). The walls of the reactor facing the transducer acted as reflectors promoting standing pressure waves. The induced power was fine-tuned from the power generator unit.

Figure 1. Structural design of the acoustic reactor chamber. 


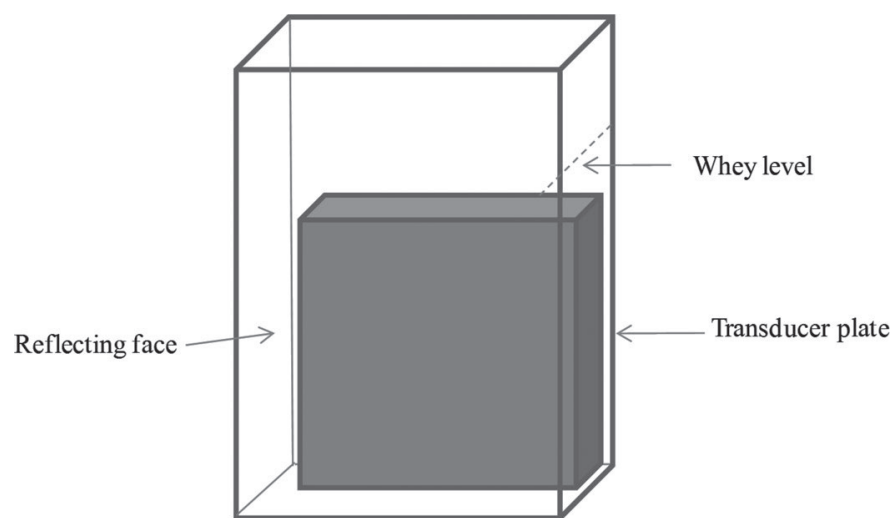

Figure 2. Schematic diagram of the separation vessel including a plate transducer (400 and 1,000 kHz).

\section{Experimental Procedure}

Gravity separation treatments were carried out in a food-grade environment at the CSIRO Food Processing Centre in a laminar flow cabinet to prevent microbial contamination. Freshly pasteurized whey $(900 \mathrm{~mL})$ was placed in the mentioned acoustic reactor and covered with aluminum foil to avoid direct light exposure. Gravity separation (creaming) trials were carried out at $37^{\circ} \mathrm{C}$ for 5,10 , and $30 \mathrm{~min}$, with and without simultaneous application of ultrasound (ultrasound off or on, respectively), to obtain a fat-enriched top layer (L1) and a fat-depleted bottom layer (L2). The vessel was placed in a water bath, and temperature was maintained constant during control and sonication trials at $37 \pm 1^{\circ} \mathrm{C}$ to ensure fat droplets were in a liquid state. Ultrasound treatments were carried out at 400 and $1,000 \mathrm{kHz}$ using the same net power level (matched power of $70 \mathrm{~W}$ ) as well as 50 and $100 \%$ power intensity, respectively (Table 1 ).

Subsequently, the original liquid whey volume in the gravity separation reactor (time 0 control) and predefined (nonsonicated and sonicated) reactor top and bottom volume fractions L1 (100 mL) and L2 (800 $\mathrm{mL})$, respectively, were fully transferred to freeze-dryer trays. Fractions were collected using 10-mL automatic pipettes. The full fat whey and its collected fractions were lyophilized using a pilot scale cabinet freeze dryer (Virtis Genesis 35 EL, SP Scientific, Warminster, PA).

The freeze-dried skimmed powdered whey (L2) was subsampled in amber vials, which were stored at ambient temperature in the dark. Samples were periodically drawn at d $0,1,3,6,8$, and 14 , and their oxidative compound profile was monitored via gas chromatography (as explained in Analysis of Lipid OxidationDerived Volatile Compounds).

\section{Ultrasound Reactor Characterization}

The reactor was characterized by measuring power input, specific energy and acoustic pressure at different treatment conditions in a model matrix medium (Milli-Q water; Merck Millipore, Bayswater VIC, Australia). Measurements are summarized in Table 1 and explained below.

Power Measurement. Net electrical power delivered into the transducer plates was measured by a powermeter (Belkin, Playa Vista, CA) and was determined by Equation [1]:

$$
\mathrm{NP}=\mathrm{TP}-\mathrm{SP}
$$

where NP, TP, and SP are net electrical power consumed by the transducer, total power input into the transducer, and generator and power used by the generator at standby mode.

Calorimetric Properties. Energy input in the reactor (water or whey matrix) during ultrasound treatment was determined by monitoring temperature increase for $300 \mathrm{~s}$ by a digital thermometer. Temperature increase was interpreted into power and specific energy using following equations:

$$
\mathrm{P}=\mathrm{mc} \frac{\Delta \mathrm{T}}{\Delta \mathrm{t}}
$$

\begin{tabular}{|c|c|c|c|c|c|c|c|}
\hline $\begin{array}{l}\text { Frequency } \\
(\mathrm{kHz})\end{array}$ & $\begin{array}{l}\text { Power setting } \\
(\%)\end{array}$ & $\begin{array}{l}\mathrm{SPL} \\
(\mathrm{kPa})\end{array}$ & $\begin{array}{l}\mathrm{NP} \\
(\mathrm{W})\end{array}$ & $\begin{array}{l}\mathrm{CP} \\
(\mathrm{W})\end{array}$ & \multicolumn{3}{|c|}{ Specific energy $(\mathrm{kJ} / \mathrm{kg})$} \\
\hline \multirow{2}{*}{400} & 50.0 & 182 & $114.0 \pm 1.5$ & $66.0 \pm 1.3$ & $23.4 \pm 2.1$ & $46.0 \pm 1.0$ & $138.0 \pm 3.0$ \\
\hline & 100 & 266 & $223.0 \pm 2.5$ & $143.0 \pm 3.2$ & $53.2 \pm 2.3$ & $100 \pm 2.2$ & $300.0 \pm 6.0$ \\
\hline \multirow[t]{2}{*}{1,000} & 17.5 & 155 & $70.0 \pm 1.8$ & $46.0 \pm 1.0$ & $18.4 \pm 1.0$ & $35.5 \pm 0.75$ & $93.5 \pm 2.5$ \\
\hline & 50.0 & 216 & $179.0 \pm 2.6$ & $95.5 \pm 1.5$ & $31.2 \pm 2.0$ & $67.0 \pm 1.0$ & $201.0 \pm 3.0$ \\
\hline
\end{tabular}

Table 1. Power and energy characteristics of ultrasound treatment at 400 and $1,000 \mathrm{kHz}^{1,2}$

${ }^{1}$ Values are averages of triplicate analysis \pm SD of 3 individual runs.

${ }^{2} \mathrm{SPL}=$ sound pressure level; $\mathrm{NP}=$ net power draw; $\mathrm{CP}=$ calorimetric power - in water. 


$$
\mathrm{Q}=\mathrm{c} \Delta \mathrm{T},
$$

where $\mathrm{P}, \mathrm{m}, \mathrm{c}, \mathrm{T}, \mathrm{Q}$, and $\mathrm{t}$ are power $(\mathrm{W})$, mass $(\mathrm{g})$, specific heat capacity $\left(\mathrm{J} / \mathrm{g} \cdot{ }^{\circ} \mathrm{C}\right)$, temperature $\left({ }^{\circ} \mathrm{C}\right)$, specific energy $(\mathrm{kJ} / \mathrm{kg})$, and time $(\mathrm{s})$, respectively.

Net electrical power ranged from 70 to $233 \mathrm{~W}$ and 70 to $345 \mathrm{~W}$ at 400 and $1,000 \mathrm{kHz}$, respectively. Specific energy ranged from 16 to $300 \mathrm{~kJ} / \mathrm{kg}$ and 18 to $390 \mathrm{~kJ} /$ $\mathrm{kg}$ at 400 and $1,000 \mathrm{kHz}$, respectively (Table 1).

Acoustic Pressure. A needle hydrophone (model HNC-1000, Onda Corp., Sunnyvale, CA) connected to an oscilloscope (TDS 2022C, Tektronix, Beaverton, OR) was used to receive, digitize, and measure ultrasound waves and calculate the acoustic intensity. The transducer was tuned to power input \% described in Experimental Procedure (matched power, 50 and 100\%) sonicating deionized water. Sound signals were monitored as peak to peak voltage $(\mathrm{Vp}-\mathrm{p})$ and expressed as the average recording during a 1-min time range. The sound pressure level $(\mathrm{Pa})$ was measured in reference to sound intensity of $6.7 * 10^{-19} \mathrm{~W} / \mathrm{m}^{2}$ in water. Sound pressure ranged from 150 to $266 \mathrm{kPa}$ and 155 to 302 $\mathrm{kPa}$ at 400 and $1,000 \mathrm{kHz}$, respectively (Table 1 ).

\section{Whey Lipid Analysis}

Extraction of Total Whey Lipid. The total fat of all whey powders (full-cream, fat-enriched, and fat-depleted fractions) was solvent extracted using a modified Bligh and Dyer method (Bligh and Dyer, 1959). Whey powder was directly weighed $(0.5 \mathrm{~g})$ into a 20 -mL amber vial. The sample was hydrated by adding $2 \mathrm{~mL}$ of water (Milli-Q grade). Lipid in the hydrated whey powder was extracted by addition of methanol:chloroform $(7.5 \mathrm{~mL}$; $2: 1 \mathrm{vol} / \mathrm{vol})$ and chloroform $(2.5 \mathrm{~mL})$ consecutively in 2 separate stages and mixed for $30 \mathrm{~min}$. Phase separation was achieved by addition of saline water $(2.5 \mathrm{~mL} ; 0.9 \%$, $\mathrm{NaCl}$ wt/vol). Undissolved whey solid was separated by centrifugation $\left(1,800 \times g\right.$ for 15 min at $5^{\circ} \mathrm{C}$; Sorvall RC 5C Plus, Thermo Fisher Scientific Inc., Waltham, MA). The aqueous top layer was discarded and bottom layer (methanol: chloroform) was collected and stored in a freezer at $-20^{\circ} \mathrm{C}$. Undissolved whey solid was reextracted using the procedure described above. Both methanol:chloroform layers were combined and residual water content was removed by addition of anhydrous $\mathrm{Na}_{2} \mathrm{SO}_{4}$. The extract was stored at $-20^{\circ} \mathrm{C}$. The whey lipid extract was used for the quantification of total lipid and polar lipid fractions.

Whey Lipid Content. An aliquot of solvent extract of total whey lipid was transferred into tared amber vials and solvent was evaporated to dryness at $60^{\circ} \mathrm{C}$ under gentle pure of nitrogen gas. Total lipid in each sample was calculated using Equation [4]:

$$
\begin{aligned}
& \text { total lipid in powder } \%= \\
& \frac{\left(\begin{array}{c}
\text { weight of vial after evaporation }- \text { weight } \\
\text { of empty vial }
\end{array}\right)}{\text { weight of whey powder }} \times 100 \text {. }
\end{aligned}
$$

\section{Whey Polar Lipid Profiling by HPLC}

Polar lipid separation and identification was performed by normal phase HPLC using a method described by Rombaut et al. (2005) with modification. A Thermofisher Ultimate 3000 Series HPLC equipped with quaternary HPLC pump and an ESA Chromachem ELSD (nebulizing gas, nitrogen at 1.8 bars and $40^{\circ} \mathrm{C}$; evaporation temperature, $60^{\circ} \mathrm{C}$ ) were used. Separations were carried out on a normal phase Prevail silica column (length $150 \mathrm{~mm}$, internal diameter $4.6 \mathrm{~mm}$, particle size $3 \mu \mathrm{m}$; Grace Davison Discovery Sciences, Rowville, VIC, Australia). An aliquot of chloroform/ methanol extracted whey fat $(1.5 \mathrm{~mL})$ was filtered through PTFE syringe filters $(25 \mathrm{~mm}$ diameter, 0.45 $\mu \mathrm{m}$ pore size) and transferred into HPLC vial. Polar lipids fractions such as phosphatidylethanolamine (PE), phosphatidyl inositol (PI), phosphatidylserine (PS), phosphatidylcholine (PC), and sphingomyelin (SM) in methanol: chloroform extract of whey lipid were separated by binary gradient created using following solvent system: solvent A: chloroform/methanol/buffer (1 M formic acid, neutralized to $\mathrm{pH} 3$ with triethylamine), 87.5:12:0.5 ( $\mathrm{vol} / \mathrm{vol} / \mathrm{vol}$ ) and solvent B: chloroform/ methanol/buffer, 28:60:12 (vol/vol/vol). The sample was initially eluted with solvent A (100\%) for $7 \mathrm{~min}$ followed by a linear gradient of 0 to $100 \%$ solvent B in solvent A from 7 to $27 \mathrm{~min}$. Flow rate of mobile bile phase and injection volume was set at $0.5 \mathrm{~mL} / \mathrm{min}$ and $25 \mu \mathrm{L}$, respectively. Polar lipid classes were identified using pure standards (Avanti Polar Lipids, Alabaster, $\mathrm{AL}$ ) of PE, PI, PS, PC, and SM. Quantitative analysis of phospholipid classes was achieved by external calibration curve methodology.

\section{Analysis of Lipid Oxidation-Derived Volatile Compounds}

Lipid oxidation-derived volatile compounds in the Cheddar cheese whey powders (control and fat-depleted L2) during storage were analyzed with an Agilent gas chromatography mass spectrometry system (GCMS6890N model GC and 5975B model MSD) equipped 
with a CombiPAL robotic autosampler (CTC Analytics AG, Zwingen, Switzerland). The sample (200 mg) was mixed with internal standard solution (2-methyl3-heptanone and 2-ethyl butanoic acid in methanol) in a 22-mL headspace vial. Lipid oxidation-derived volatile compounds in the whey sample vial were extracted/concentrated on the solid-phase microextraction (SPME) fiber (carboxen/polydimethylsiloxane; 85 $\mu \mathrm{m}$ film thickness; $10 \mathrm{~mm}$ long; Supelco, Bellefonte, $\mathrm{PA}$ ) for $30 \mathrm{~min}$ at $50^{\circ} \mathrm{C}$. The SPME-sampled volatiles were thermally desorbed in the GC inlet (PTV inlet, $260^{\circ} \mathrm{C}$, set in splitless mode, splitless time $1.0 \mathrm{~min}$ ) and chromatographed on a VF-WAXms column $(30 \mathrm{~m} \times$ $0.32 \mathrm{~mm} \times 1.0 \mu \mathrm{m}$; Varian Inc., Mulgrave, Victoria, Australia) using a temperature gradient of 35 to $225^{\circ} \mathrm{C}$ at $10^{\circ} \mathrm{C} / \mathrm{min}$ with initial and final hold times of 3 and $10 \mathrm{~min}$, respectively. Eluted compounds were detected by the MS detector. The MS conditions were as follows: capillary direct interface temperature, $260^{\circ} \mathrm{C}$; ionization energy, $70 \mathrm{eV}$; mass range, 30 to $300 \mathrm{amu}$; and scan rate, 5 scans/s. Compounds were identified by comparison of collected mass spectra with spectra in NIST08 database (National Institute of Standards Technology mass spectral search program; NIST, Gaithersburg, $\mathrm{MD}$ ), linear retention indices (determined using a set of saturated alkanes C7-C22), and spectra of an authentic standard. Semiquantitative analysis was performed using internal standard methodology, where peak areas were normalized to the internal standard (std) to determine the relative abundance of the compounds $(\mathrm{cmpd})$ of interest:

$$
\begin{aligned}
& \text { std cmpd conc }+ \text { detected } \\
& \frac{\text { cmpd peak area }}{\text { std cmpd peak area }}=\text { detected cmpd conc. [5] }
\end{aligned}
$$

Samples were analyzed in duplicate, and differences between replicate analyses were less than $5 \%$.

\section{Statistical Analysis}

A 2-way ANOVA using general linear model with a 95\% level of significance (Minitab 16, Minitab Ltd., Coventry, UK) was used to compare total fat content and volatile compounds in whey powders at different frequencies, power input, and treatment times. The post hoc test used to separate the means was Tukey's honestly significant difference test.

\section{RESULTS AND DISCUSSION}

\section{Ultrasound-Assisted Gravity Separation of Whey Fat}

Table 2 summarizes the concentration of fat determined in the top layer L1, relative to the total fat in the original whey, at increasing gravity separation (or creaming) time, without and with ultrasound application. Gravity separation of fat in nonsonicated control samples significantly $(P<0.05)$ increased with creaming time (Table 2). Ultrasound treatment further enhanced gravity separation of fat for all tested conditions at increasing time and power input, which coincides with observations provided by Leong et al. (2014b) for fat in raw milk and by Nii et al. (2009) for a canola oil emulsion. Greater power input and sonication time further promoted creaming (Table 2). At both tested frequencies $(400$ and $1,000 \mathrm{kHz}$ ), the sound pressure (Table 1) was above the threshold value to form bands (50-200 $\mathrm{kPa}$; Miles et al., 1995), which led to fat particle aggregation across the standing wave field, thereby resulting in enhanced creaming.

The extent of fat separation was significantly $(P<$ $0.05)$ higher after $30 \mathrm{~min}$ sonication at $400 \mathrm{kHz}(223$ $\mathrm{W})$ and $1,000 \mathrm{kHz}(345 \mathrm{~W})$, leaving a residual fat content in the bottom layer L2 of 5.5 and $4.2 \%$ (wt/wt, L2 powder basis) or 0.29 and $0.22 \%$ (wt/vol, L2 liquid basis), respectively. Highest separation was achieved at $1,000 \mathrm{kHz}(P<0.05)$, in comparison to $400 \mathrm{kHz}$, at

Table 2. Percentage fat in freeze-dried top layers $(\mathrm{g} / 100 \mathrm{~g}$ of fat in $\mathrm{L} 1$ whey powder) collected after

\begin{tabular}{|c|c|c|c|c|}
\hline \multirow{2}{*}{$\begin{array}{l}\text { Frequency } \\
(\mathrm{kHz})\end{array}$} & \multirow{2}{*}{$\begin{array}{l}\text { Net power } \\
\text { draw }(\mathrm{W})\end{array}$} & \multicolumn{3}{|c|}{ Separation time ${ }^{1}(\min )$} \\
\hline & & 5 & 10 & 30 \\
\hline 0 & 0 & $5.4 \pm 0.4^{\mathrm{a}}$ & $7.4 \pm 0.8^{\mathrm{b}}$ & $8.2 \pm 3.1^{\mathrm{b}}$ \\
\hline \multirow[t]{3}{*}{400} & $70^{1}$ & $16.1 \pm 1.5^{\mathrm{c}}$ & $16.7 \pm 2.2^{\mathrm{c}}$ & $18.8 \pm 2.2^{\mathrm{c}}$ \\
\hline & 114 & $16.0 \pm 2.5^{\mathrm{c}}$ & $18.7 \pm 2.1^{\mathrm{c}}$ & $20.7 \pm 1.5^{\mathrm{c}}$ \\
\hline & 223 & $23.1 \pm 1.5^{\mathrm{d}}$ & $25.0 \pm 2.1^{\mathrm{d}}$ & $30.0 \pm 2.1^{\mathrm{e}}$ \\
\hline \multirow[t]{3}{*}{1,000} & $70^{2}$ & $15.3 \pm 2.5^{\mathrm{c}}$ & $16.6 \pm 1.5^{\mathrm{c}}$ & $20.2 \pm 2.4$ \\
\hline & 179 & $24.3 \pm 1.5^{\mathrm{d}}$ & $31.8 \pm 1.5^{\mathrm{e}}$ & $36.8 \pm 1.4^{e}$ \\
\hline & 345 & $33.9 \pm 4.2^{\mathrm{e}}$ & $39.3 \pm 2.1^{\mathrm{e}}$ & $43.5 \pm 3.2^{\mathrm{f}}$ \\
\hline
\end{tabular}
nonultrasound and ultrasound gravity separation at various frequencies, power input, and treatment times

${ }^{\mathrm{a}-\mathrm{f}}$ Significant differences $(P<0.05)$ are labeled with different superscript letters.

${ }^{1}$ Averages of triplicate analysis $\pm \mathrm{SE}$ of 3 individual runs.

${ }^{2}$ Matched power. 
Table 3. Concentration of aldehydes $(\mu \mathrm{g} / \mathrm{kg})$ and their odor threshold values in nonultrasound and ultrasound gravity-separated bottom layer whey powder (L2) treated at 400 and $1,000 \mathrm{kHz}$ for $30 \mathrm{~min}$ and stored for up to $14 \mathrm{~d}^{1}$

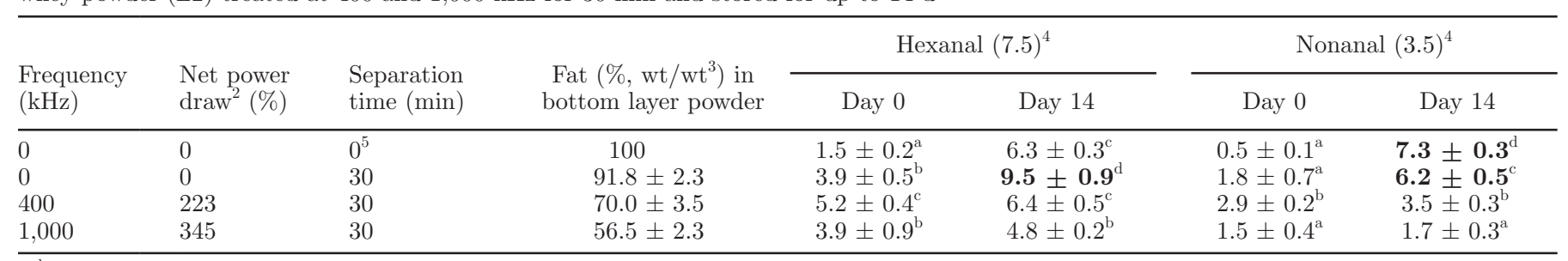

${ }^{\mathrm{a}-\mathrm{d}}$ Significant differences $(P<0.05)$ are labeled with different superscript letters. The bolded numbers highlight values above the human odor detection threshold.

${ }^{1}$ Values are averages of triplicate analysis \pm SE of 3 individual runs.

${ }^{2}$ Maximum net power draw at 400 and $1,000 \mathrm{kHz}$.

${ }^{3}$ Grams of fat in bottom layer/100 g of fat in original whey powder sample.

${ }^{4}$ Concentration values $(\mu \mathrm{g} / \mathrm{kg})$ presented in parentheses represent the human odor detection threshold, obtained from Buttery et al. (1978, 1988) and Sigrist et al. (2000).

${ }^{5}$ No gravity separation of fat in layers has occurred.

maximum power draw for all tested separation times. This is due to the higher power delivered by the 1,000 $\mathrm{kHz}$ transducer at maximum power draw. However, a matched power draw of $70 \mathrm{~W}$ at both 400 and 1,000 $\mathrm{kHz}$, provided equivalent fat concentration at the top layer across tested separation times. Therefore, no significant differences $(P>0.05)$ were observed between 400 and $1,000 \mathrm{kHz}$ in assisting whey fat separation at equivalent specific energy inputs and sound pressure levels. Leong et al. (2014a) showed that fat separation from whole raw milk was better achieved at frequencies greater than $1 \mathrm{MHz}$ due to the presence of smaller sized fat globules. As a result of the cheese making process, whey has a more heterogeneous fat droplet size distribution that includes free fat, liposomes, and fat globules.

Fat separated at maximum power draw after $30 \mathrm{~min}$ was 4 to 5 times higher than the fat separated by nonsonicated gravity separation. However, optimization of processing conditions and reactor design are required to further enhance fat separation. For example, more efficient ultrasound-assisted fat separation was demonstrated to occur in raw milk near room temperature by increasing specific energy, either by reducing the transducer-reflector distance, or by positioning milk between dual parallel transducers (Leong et al., 2014a,b). Another important aspect is the size separation of fat droplets, in particular because industrial centrifugation cannot separate smaller fat droplets in whey. Leong et al. (2016) recently demonstrated that exposure of raw milk in a batch $(1.8 \mathrm{~L})$ ultrasound standing wave system $(2 \mathrm{MHz}, 300 \mathrm{~W} / \mathrm{L})$ up to $20 \mathrm{~min}$ can separate smaller sized globules. This therefore provides the opportunity to separate fat droplets according to their size fractions.
As described earlier, ultrasound-assisted fat separation was the result of acoustic forces in the standing wave field applied on the fat droplets in the whey. In this study it was observed that as the sonication progressed, fat droplets were displaced toward the container wall, acting as an antinode. That pattern was also noticed by Juliano et al. (2011) in a recombined milk emulsion, indicating that in larger scale vessels it is difficult to achieve a perfect geometry and therefore the antinodes may shift their position across the standing wave field (Juliano et al., 2011).

\section{Oxidative Stability of Fat-Depleted Whey Powders}

The GC-MS volatile profile of full-fat and fat-depleted (bottom layer L2) whey powders consisted of shortchain fatty acids, alcohols, ketones, esters, aldehydes, as well as sulfur-containing compounds, cyclic terpenes, alkyl pyrazine, and pyrans. This study focused on the oxidative stability of whey lipids and therefore only lipid oxidation-derived compounds (i.e., aldehydes, alcohols, acids, and ketones) are presented and discussed. As seen in our previous study (Torkamani et al., 2014), pasteurization treatment significantly contributed to ketone, aldehyde, and alcohol generation in whey, which primarily was the result of degradation of the hydroperoxide present in whey. Table 3 reports the 2 major lipid oxidation-derived aldehydes, namely hexanal and nonanal, which were detected and quantified in powders from nonsonicated (full-fat and fat-depleted) and sonicated (fat-depleted) whey. The table data were obtained after maximum ultrasound exposure (30 min separation, maximum specific energy). Hexanal and nonanal are often attributed to oxidative rancidity in milk and dairy products (Cadwallader and Singh, 2009), 
Table 4. Concentration of individual and total polar lipids (PL) in original whey and the respective phospholipid fractions obtained in the bottom layer L2 after nonultrasound and ultrasound-assisted gravity separation for 0,5 , or $30 \mathrm{~min}$

\begin{tabular}{|c|c|c|c|c|c|c|c|c|c|c|}
\hline \multirow[b]{2}{*}{$\mathrm{PL}^{1}$} & \multirow{2}{*}{$\begin{array}{l}\text { Frequency } \\
(\mathrm{kHz})\end{array}$} & \multirow{2}{*}{$\begin{array}{l}\text { Net power } \\
\operatorname{draw}^{2}(\mathrm{~W})\end{array}$} & \multicolumn{3}{|c|}{$\begin{array}{l}\text { Phospholipid concentration } \\
\text { ( } \mu \mathrm{g} / 100 \mathrm{~g} \text { of powder })\end{array}$} & \multicolumn{3}{|c|}{$\begin{array}{l}\text { Phospholipid concentration } \\
\text { ( } \mu \mathrm{g} / 100 \mathrm{~g} \text { of fat })\end{array}$} & \multicolumn{2}{|c|}{$\begin{array}{c}\text { Relative change after } \\
\text { ultrasound } \\
(\mu \mathrm{g} / 100 \mathrm{~g} \text { of } \mathrm{PL} \text { at time } 0)\end{array}$} \\
\hline & & & $0^{5}$ & 5 & 30 & $0^{5}$ & 5 & 30 & 5 & 30 \\
\hline \multirow[t]{3}{*}{$\mathrm{PE}$} & $0^{6}$ & 0 & $31.5 \pm 0.5$ & $17.9 \pm 0.3$ & $16.5 \pm 0.7$ & 331.0 & 197.8 & 182.4 & - & - \\
\hline & 400 & 223 & & $19.5 \pm 0.6$ & $16.9 \pm 0.2$ & & 234.4 & 215.0 & 11 & 10 \\
\hline & 1,000 & 345 & & $15.1 \pm 1.6$ & $12.5 \pm 0.7$ & & 188.4 & 168.2 & -3 & -4 \\
\hline \multirow[t]{3}{*}{ PI } & $0^{6}$ & 0 & $2.7 \pm 0.1$ & $1.3 \pm 0.1$ & $1.1 \pm 0.2$ & 28.4 & 14.4 & 12.2 & - & - \\
\hline & 400 & 223 & & $1.4 \pm 0.1$ & $1.0 \pm 0.2$ & & 16.7 & 12.7 & 8 & 2 \\
\hline & 1,000 & 345 & & $1.1 \pm 0.5$ & $0.9 \pm 0.2$ & & 13.7 & 12.1 & -2 & 0 \\
\hline \multirow{3}{*}{ PS } & $0^{6}$ & 0 & $5.4 \pm 0.1$ & $3.8 \pm 0.1$ & $3.3 \pm 0.1$ & 56.7 & 42.0 & 36.5 & - & - \\
\hline & 400 & 223 & & $4.2 \pm 0.1$ & $2.8 \pm 0.3$ & & 50.5 & 35.6 & 15 & -1 \\
\hline & 1,000 & 345 & & $3.5 \pm 0.2$ & $2.6 \pm 0.4$ & & 43.7 & 35.0 & 3 & -3 \\
\hline \multirow[t]{3}{*}{$\mathrm{PC}$} & $0^{6}$ & 0 & $22.5 \pm 0.5$ & $14.5 \pm 0.1$ & $13.5 \pm 0.7$ & 236.5 & 160.3 & 149.2 & - & - \\
\hline & 400 & 223 & & $16.7 \pm 0.4$ & $16.0 \pm 0.3$ & & 200.8 & 203.6 & 17 & 23 \\
\hline & 1,000 & 345 & & $12.6 \pm 1.4$ & $13.6 \pm 0.5$ & & 157.2 & 183.0 & -1 & 14 \\
\hline \multirow[t]{3}{*}{$\mathrm{SM}$} & $0^{6}$ & 0 & $28.2 \pm 0.7$ & $17.6 \pm 0.4$ & $16.9 \pm 2.4$ & 295.9 & 194.5 & 186.8 & - & - \\
\hline & 400 & 223 & & $20.4 \pm 0.8$ & $19.8 \pm 0.6$ & & 245.2 & 251.9 & 17 & 22 \\
\hline & 1,000 & 345 & & $17.5 \pm 1.7$ & $20.2 \pm 1.7$ & & 218.4 & 257.0 & 8 & 24 \\
\hline \multirow[t]{3}{*}{ Total PL } & $0^{6}$ & 0 & $90.1 \pm 1.4$ & $55.2 \pm 0.5$ & $51.3 \pm 2.9$ & 945.7 & 610.1 & 567.0 & - & - \\
\hline & 400 & 223 & & $62.3 \pm 1.9$ & $56.2 \pm 0.9$ & & 749.0 & 715.0 & 15 & 16 \\
\hline & 1,000 & 345 & & $49.8 \pm 4.9$ & $59.8 \pm 2.8$ & & 621.5 & 804.8 & 1 & 25 \\
\hline
\end{tabular}

${ }^{1}$ Phosphatidylethanolamine (PE), phosphatidylinositol (PI), phosphatidylserine (PS), phosphatidylcholine (PC), sphingomyelin (SM).

c. $\quad{ }^{2}$ Maximum net power draw at 400 and $1,000 \mathrm{kHz}$.

${ }^{3}$ Averages of triplicate analysis \pm SE of 3 individual runs.

党 ${ }^{4}$ Calculated from the difference between PL species concentration after separation (without or with ultrasound treatment) over the original PL species concentration in the whey 음 sample.

Pepresents original whole-fat whey sample.

$2 \quad{ }^{6}$ Control samples. 
and relatively small changes in their concentration can negatively affect whey flavor. For comparison, Table 3 also includes the published odor detection thresholds of these compounds in water in micrograms per kilogram or parts per billion.

Hexanal concentration in full-fat whey powder was below the published odor threshold value of $7.5 \mu \mathrm{g} /$ $\mathrm{kg}$ at $\mathrm{d} 0$ and 14 of room temperature storage (Table 3 ). However, nonanal measured after $14 \mathrm{~d}$ was beyond the odor threshold value. Fat-reduced whey powder using gravity separation for $30 \mathrm{~min}$ exceeded the odor threshold value for both hexanal and nonanal after 8 and $6 \mathrm{~d}$ of storage. For ultrasound-assisted fat-reduced whey powders, however, lipid oxidation-derived volatile compounds remained below the odor threshold values for up to $14 \mathrm{~d}$ storage. Hexanal and nonanal concentrations found in 1,000 kHz whey powders (bottom layer) were significantly $(P<0.05)$ lower than in powders from whey treated at $400 \mathrm{kHz}$, due to greater creaming efficiency and lower fat content at maximum net power input and 30 min sonication time.

In our previous study (Torkamani et al., 2014), we characterized the production of free radicals in the same ultrasound reactor by determining the cavitational yield, using a colorimetric method that quantifies the amount of hydrogen peroxide (or hydroxyl radical equivalents) produced by ultrasound. Ultrasonication of water in the reactor system resulted in greater amounts of hydroxyl radicals with higher power input, acoustic pressure, and time, particularly at 400 and 1,000 kHz. The potential development of oxidation compounds during the storage of sonicated whey powder was of concern.

Even when the highest specific energy inputs were applied at 400 and $1,000 \mathrm{kHz}$ (maximum $390 \mathrm{~kJ} / \mathrm{kg}$ ), ultrasound did not promote oxidation reactions in fatreduced whey powders. The improvement seen in oxidative stability of ultrasound fat-depleted whey powders could be due to the combined effect of reduced-fat content in whey powders and the diminishing ratio of remaining lipids to natural antioxidants such whey proteins (e.g., lactoferrin and AA); antioxidants possibly had a higher capacity for quenching free radicals or for chelation of metal ions to prevent further oxidation (Browdy and Harris, 1997; Tong et al., 2000). It is common industry practice that the whey powders remain in dry storage for extended periods up a year. Typical industrial centrifuges operating at $\sim 3,000 \times g$ can provide skim whey between 0.04 and $0.07 \%$. In comparison, ultrasound applied in these experiments was able to reduce fat concentration in whey from $0.41 \%$ up to $0.23 \%$ ( $\sim 56 \%$ reduction) at $1 \mathrm{MHz}$ and highest specific energy. Further optimization should be considered taking into account the stability and functionality of the resulting whey powder throughout longer storage periods.

\section{Ultrasound Effect on Polar Lipid Partition}

Concentration of polar lipids detected and quantified in full-fat and fat-depleted (bottom layer L2) whey powders are summarized as a function of separation time and frequency input in Table 4. All major phospholipids present in milk such as PI, PE, PS, PC, and SM were detected in all freeze-dried whey samples. In our previous study (Torkamani et al., 2014), we reported that similar ultrasound treatments and associated localized sound pressure did not trigger reactions resulting in phospholipid degradation in full cream whey. In the current study, fat-depleted (L2) powders decreased the concentration of individual phospholipids as a result of gravity separation of fat (with and without ultrasound). Separation time did not clearly affect the separation of phospholipid species in comparison to the original full fat whey powder (Table 4). The contribution of ultrasound assisted separation to phospholipid partitioning from L2 to L1 (fat-enriched layer) was relatively small for both 400 and 1,000 kHz. Therefore, little or no preferential partitioning of phospholipids toward the top fat-enriched layer was detected after ultrasound gravity-assisted separation.

\section{ACKNOWLEDGMENTS}

The authors acknowledge the guidance from Mary Ann Augustin (CSIRO, Werribee, Australia) and the assistance of Derrick D'Souza in the analytical trials. We also thank Kai Knoerzer (CSIRO) for internally reviewing the manuscript.

\section{REFERENCES}

Bligh, E. G., and W. J. Dyer. 1959. A rapid method of total lipid extraction and purification. Can. J. Biochem. Physiol. 37:911-917.

Browdy, A. A., and N. D. Harris. 1997. Whey improves oxidative stability of soybean oil. J. Food Sci. 62:348-350.

Buttery, R. G., D. G. Guadagni, and L. C. Ling. 1978. Volatile aroma components of cooked artichoke. J. Agric. Food Chem. 26:791-793.

Buttery, R. G., J. G. Turnbaugh, and L. C. Ling. 1988. Contribution of volatiles to rice aroma. J. Agric. Food Chem. 36:1006-1009.

Cadwallader, K. R., and T. K. Singh. 2009. Flavours and off flavours in milk and milk products. Pages 631-690 in Advanced Dairy Chemistry: Lactose, Water, Salts and Minor. Vol. 3. Springer, New York, NY.

Chouliara, E., K. G. Georgogianni, N. Kanellopoulou, and M. G. Kontominas. 2010. Effect of ultrasonication on microbiological, chemical and sensory properties of raw, thermized and pasteurized milk. Int. Dairy J. 20:307-313.

Juliano, P., A. Kutter, L. J. Cheng, P. Swiergon, R. Mawson, and M. A. Augustin. 2011. Enhanced creaming of milk fat globules in milk emulsions by the application of ultrasound and detection by means of optical methods. Ultrason. Sonochem. 18:963-973. 
Juliano, P., P. Swiergon, R. Mawson, K. Knoerzer, and M. A. Augustin. 2013b. Application of ultrasound for oil separation and recovery of palm oil. J. Am. Oil Chem. Soc. 90:579-588.

Juliano, P., S. Temmel, M. Rout, P. Swiergon, R. Mawson, and K. Knoerzer. 2013a. Creaming enhancement in a liter scale ultrasonic reactor at selected transducer configurations and frequencies. Ultrason. Sonochem. 20:52-62.

Juliano, P., A. E. Torkamani, T. Leong, V. Kolb, P. Watkins, S. Ajlouni, and T. K. Singh. 2014. Lipid oxidation volatiles absent in milk after selected ultrasound processing. Ultrason. Sonochem. $21: 2165-2175$.

Leong, T., L. Johansson, P. Juliano, R. Mawson, S. McArthur, and R. Manasseh. 2014a. Design parameters for the separation of fat from natural whole milk in an ultrasonic litre-scale vessel. Ultrason. Sonochem. 21:1289-1298.

Leong, T., L. Johansson, P. Juliano, S. L. McArthur, and R. Manasseh. 2013. Ultrasonic separation of particulate fluids in small and large scale systems: A review. Ind. Eng. Chem. Res. 52:16555-16576.

Leong, T., L. Johansson, R. Mawson, S. L. McArthur, R. Manasseh, and P. Juliano. 2016. Ultrasonically enhanced fractionation of milk fat in a litre-scale prototype vessel. Ultrason. Sonochem. 28:118129.

Leong, T., P. Juliano, L. Johansson, R. Mawson, S. L. McArthur, and R. Manasseh. 2014b. Temperature effects on the ultrasonic separation of fat from natural whole milk. Ultrason. Sonochem. 21:2092-2098.

Marchesini, G., S. Balzan, F. Montemurro, L. Fasolato, I. Andrighetto, S. Segato, and E. Novelli. 2012. Effect of ultrasound alone or ultrasound coupled with $\mathrm{CO}_{2}$ on the chemical composition, cheesemaking properties and sensory traits of raw milk. Innov. Food Sci. Emerg. Technol. 16:391-397.
Mason, T. J., A. J. Cobley, J. E. Graves, and D. Morgan. 2011. New evidence for the inverse dependence of mechanical and chemical effects on the frequency of ultrasound. Ultrason. Sonochem. 18:226-230.

Miles, C. A., M. J. Morley, W. R. Hudson, and B. M. Mackey. 1995. Principles of separating micro-organisms from suspensions using ultrasound. J. Appl. Bacteriol. 78:47-54.

Morr, C. V., and E. Y. W. Ha. 1991. Off-flavors of whey protein concentrates: A literature review. Int. Dairy J. 1:1-11.

Morr, C. V., and E. Y. W. Ha. 1993. Whey protein concentrates and isolates: Processing and functional properties. Crit. Rev. Food Sci. Nutr. 33:431-476.

Nii, S., S. Kikumoto, and H. Tokuyama. 2009. Quantitative approach to ultrasonic emulsion separation. Ultrason. Sonochem. 16:145149 .

Riener, J., F. Noci, D. A. Cronin, D. J. Morgan, and J. G. Lyng. 2009. Characterisation of volatile compounds generated in milk by high intensity ultrasound. Int. Dairy J. 19:269-272.

Rombaut, R., J. V. Camp, and K. Dewettinck. 2005. Analysis of phospho- and sphingolipids in dairy products by a new HPLC method. J. Dairy Sci. 88:482-488.

Sigrist, I., B. Wunderli, R. Pompizzi, G. G. G. Manzardo, and R. Amado. 2000. Influence of dimethyl furan fatty acid photooxidative degradation products on the flavour of green tea. Pages 554-556 in Deutsche Forschungsanstalt für Lebensmittelchemie.

Tong, L. M., S. Sasaki, D. J. McClements, and E. A. Decker. 2000. Mechanisms of the antioxidant activity of a high molecular weight fraction of whey. J. Agric. Food Chem. 48:1473-1478.

Torkamani, A. E., P. Juliano, S. Ajlouni, and T. K. Singh. 2014. Impact of ultrasound treatment on lipid oxidation of Cheddar cheese whey. Ultrason. Sonochem. 21:951-957. 